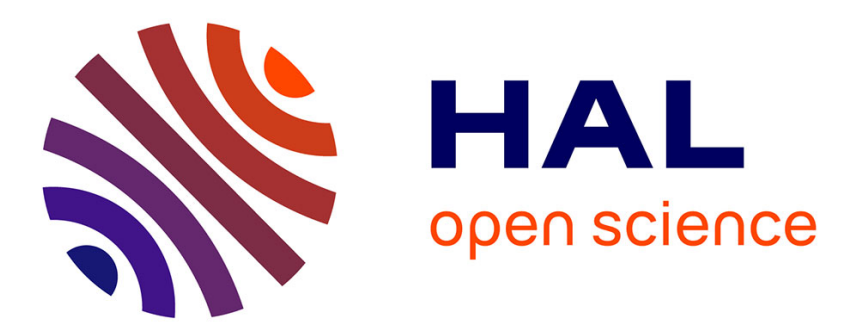

\title{
Mare basalt flooding events surrounding Chang'e-4 landing site as revealed by Zhinyu crater ejecta
}

Sheng Gou, Zongyu Yue, Kaichang Di, Roberto Bugiolacchi, Meng-Hua Zhu, Patrick C Pinet, Zhanchuan Cai

\section{- To cite this version:}

Sheng Gou, Zongyu Yue, Kaichang Di, Roberto Bugiolacchi, Meng-Hua Zhu, et al.. Mare basalt flooding events surrounding Chang'e-4 landing site as revealed by Zhinyu crater ejecta. Icarus, 2021, 360, pp.114370. 10.1016/j.icarus.2021.114370 . hal-03441633

\section{HAL Id: hal-03441633 \\ https://hal.science/hal-03441633}

Submitted on 22 Nov 2021

HAL is a multi-disciplinary open access archive for the deposit and dissemination of scientific research documents, whether they are published or not. The documents may come from teaching and research institutions in France or abroad, or from public or private research centers.
L'archive ouverte pluridisciplinaire HAL, est destinée au dépôt et à la diffusion de documents scientifiques de niveau recherche, publiés ou non, émanant des établissements d'enseignement et de recherche français ou étrangers, des laboratoires publics ou privés. 
1 Mare basalt flooding events surrounding Chang'e-4 landing site as

2 revealed by Zhinyu crater ejecta

3

4 Sheng GOU ${ }^{\mathrm{a}, \mathrm{b}, \mathrm{c}}$, Zongyu YUE ${ }^{\mathrm{b}, \mathrm{d}}$, Kaichang DI ${ }^{\mathrm{b}, \mathrm{d}, ~ *}$, Roberto BUGIOLACCHI ${ }^{\mathrm{a}, \mathrm{c}, \mathrm{f}}$,

5 Meng-Hua ZHU ${ }^{\mathrm{a}, \mathrm{c}}$, Patrick C. PINET ${ }^{\mathrm{e}}$, Zhanchuan CAI ${ }^{\mathrm{a}, \mathrm{c}}$

$6 \quad{ }^{\text {a }}$ State Key Laboratory of Lunar and Planetary Sciences, Macau University of Science

7 and Technology, Macau, China

$8 \quad{ }^{b}$ State Key Laboratory of Remote Sensing Science, Aerospace Information Research

9 Institute, Chinese Academy of Sciences, Beijing 100101, China

$10{ }^{\mathrm{c}}$ CNSA Macau Center for Space Exploration and Science, Macau, China

$11{ }^{\mathrm{d}}$ Center for Excellence in Comparative Planetology, Chinese Academy of Sciences,

12 Hefei 230026, China

13 e Institut de Recherche en Astrophysique et Planétologie, University of Toulouse,

14 CNRS, UPS, CNES, UT3, Toulouse, France

$15 \quad{ }^{\mathrm{f}}$ Earth Sciences, University College London, London, UK

16

17

18

$19 *$ Correspondence to Kaichang DI

20 Email: dikc@radi.ac.cn

21 Tel/Fax: 8610-64868229

22 Address: P.O. Box 9718, No. 20A, Datun Road, Chaoyang District, Beijing, 100101,

23 China 
Abstract

Von Kármán crater's floor was flooded with mare basalts during the Imbrian period.

27 This site is the target of China's ongoing Chang'e-4 mission that includes the Yutu-2

28 rover and its instrumental payload. The Zhinyu crater, one of the largest craters within

29 a few tens of kilometers from the landing site, is the product of a fresh impact that

30 excavated subsurface, basaltic materials onto the surface. The compositional

31 characteristics of the continuous ejecta around the crater vary radially with distance,

32 suggesting possible mineral heterogeneity at depth. At least three main mare flooding phases could have occurred within Von Kármán, producing a basalt layer of at least $320 \mathrm{~m}$ in thickness. However, a broadly consistent olivine composition (Fo\#: 55) of the three proposed basalt layers suggests that the sources of the mare basalts would have been similar in composition, perhaps even consisting of a single magma chamber where magma had time to evolve. The Yutu-2 rover that is edging its way westwards, could in principle test this hypothesis, thus further constraining the thermal history of the Von Kármán crater.

Keywords: Zhinyu crater; Von Kármán crater; Mare flooding; Homogenous composition; Single magma chamber; 


\section{Highlights}

45

46

1. Three mare flooding events occurring inside Von Kármán crater during the

$47 \quad$ Imbrian period are suggested.

48

49

2. The sources of mare basalts are almost homogenous in composition, perhaps

50 even from a single magma chamber with a moderate evolution.

51

52

3. A refined stratigraphy for low-Ti mare basalts is established and is expected to

53 be verified by the Yutu-2 rover in the near future.

54

55 


\section{Introduction}

The Von Kármán crater ( 186 km in diameter), lying in the northwest of South Pole-Aitken (SPA) basin on the lunar farside, was formed $3.97 \mathrm{Ga}$ ago in the preNectarian period (Stuart-Alexander, 1978; Yingst et al., 2017). During the Imbrian period, the floor of Von Kármán crater was flooded with several basaltic lava flows (or mare basalts) (Huang et al., 2018; Pasckert et al., 2018; Ling et al., 2019). China's Chang'e-4 probe touched down successfully in the Von Kármán crater at $177.588^{\circ} \mathrm{E}$, $45.457^{\circ} \mathrm{S}$ on January 3, 2019, and released the Yutu-2 rover to conduct in situ measurements on this previously unexplored region (Di et al., 2019a; Pinet, 2019). The surface of the Chang'e-4 landing site is generally thought to be mantled by ejecta from the Finsen crater (e.g., Gou et al., 2019; Hu et al., 2019; Gou et al., 2020; Huang et al., 2020; Lin et al., 2020), though the estimation of ejecta thickness from Finsen crater at the landing site is debated (Huang et al., 2018; Di et al., 2019b; Fu et al., 2020).

Zhinyu $\left(176.15^{\circ} \mathrm{E}, 45.34{ }^{\circ} \mathrm{S}\right)$, a fresh, simple crater with a diameter of $\sim 3.8 \mathrm{~km}$ and a depth of $\sim 800 \mathrm{~m}$ (Fig. 1) is one of the largest impacts near the Chang'e-4 landing site, lying about $30 \mathrm{~km}$ away to the west. The Zhinyu impact penetrated the mare basalts within the Von Kármán crater, thus it opens an exploratory window into the composition and stratigraphy of the subsurface. Hypervelocity impacts exhume materials from the subsurface and deposit them both within and outside the newly formed crater, allowing for investigation. For instance, Fu et al. (2020) targeted 40 dark-haloed craters and 77 bright ray craters around the Chang'e-4 landing area and 
constructed a possible stratigraphy (including a low-Ti mare basalt layer) based on the excavation depths of these craters and their distances from the Finsen crater. Further, observed differences in the ejecta layers would represent geological variations with depth at the target point. For example, Ding et al. (2020) proposed that several fresh craters surrounded by blocky fragments encountered by the Yutu- 2 rover might be secondaries of the Zhinyu crater. Since the primary source for the regolith at the Chang'e-4 landing site is reckoned to represent Finsen crater ejecta (compositionally different from mare basalt), caution must be applied in interpreting the in situ measured spectra around these secondary craters. Therefore, the Zhinyu crater ejecta provides a rare opportunity to explore the sub-regolith mare basalts, and should also contribute to the correct interpretation of the in situ measured data by the Yutu- 2 rover.

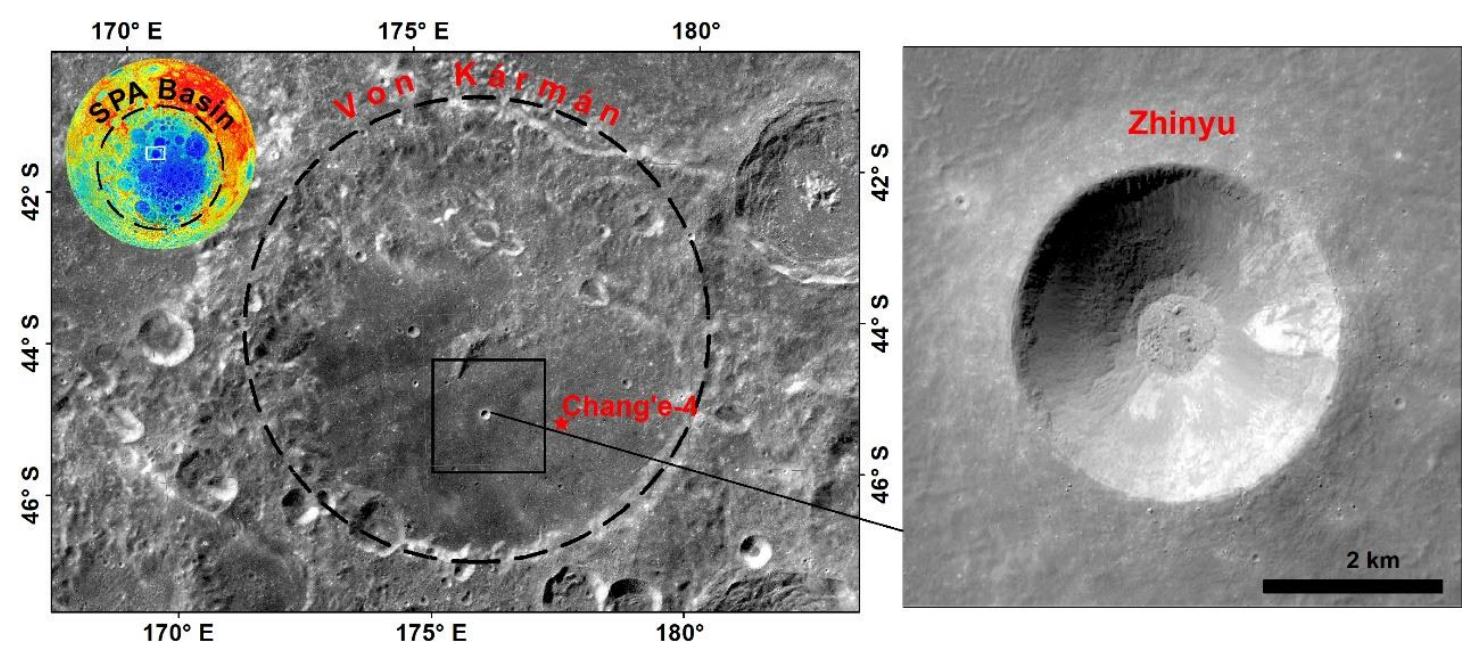

Fig. 1. Location of the Zhinyu crater inside the Von Kármán crater. The base map is a digital orthophoto map mosaic $(7 \mathrm{~m} / \mathrm{pixel})$ generated from Chang'e-2 images (Ren et al., 2014). Different colors in the inset represent different heights, with red being the highest and blue being the lowest. The white box shows the boundaries of Fig. 1. The black box frames the area of Fig. 2, Fig. 4, and Fig. 5. 


\section{Data}

97

\subsection{Moon mineralogy mapper spectra}

The Moon Mineralogy Mapper $\left(\mathbf{M}^{3}\right)$, which flew onboard India's Chandrayaan-1 lunar orbiter, was a push-broom imaging spectrometer operating from the visible into the near-infrared $(0.42-3.0 \mu \mathrm{m}) . \mathrm{M}^{3}$ observed the lunar surface both in a highresolution target mode $(80 \mathrm{~m} /$ pixel; 260 spectral channels $)$ and in a low-resolution global mode (140 m/pixel; 85 spectral channels) from a $100 \mathrm{~km}$ orbit (Pieters et al., 2009). The $\mathrm{M}^{3}$ Level 2 spectral reflectance images (REFIMG), which have been photometrically calibrated and thermal emission corrected (Clark et al., 2011; Besse et al., 2013), are used in this study to extract spectra from regions of interest (ROIs) for further detailed analysis (Supplementary Fig. 1).

\subsection{Multiband imager products and images}

The multiband imager (MI) was a high-resolution imaging camera onboard the Japanese Kaguya lunar orbiter that included separate visible and near infrared sensors (Ohtake et al., 2008). It acquired push-broom images in five bands for the visible and four bands for the near-infrared spectral ranges (Ohtake et al., 2008). The spatial resolution of the MI images is $20 \mathrm{~m} /$ pixel for the visible bands and $62 \mathrm{~m} /$ pixel for the near- infrared bands taken at a nominal orbit altitude of $100 \mathrm{~km}$ (Ohtake et al., 2008). The mineral abundance products derived from topographically-corrected MI reflectance data (Lemelin et al., 2016) are used in this study to evaluate compositional variabilities of the mare basalts. As concentrations of $\mathrm{TiO}_{2}$ and $\mathrm{FeO}$ are useful in classifying major lunar rock types (Lucey et al., 1998), derived abundances around the 

possible differences.

\section{Methods}

122

\subsection{Basalt layer identification}

There is evidence that the lava infill of the Von Kármán crater occurred during the Imbrian (Im) period (Huang et al., 2018). Inferred $\mathrm{TiO}_{2}$ content is commonly used as a classifier for basalts: very low $\mathrm{Ti}\left(<1.5 \mathrm{wt} \% \mathrm{TiO}_{2}\right)$, low- $\mathrm{Ti}\left(1.5-6 \mathrm{wt} \% \mathrm{TiO}_{2}\right)$, and high-Ti (>6 wt\% $\mathrm{TiO}_{2}$ ) (Hiesinger and Jaumann, 2014). The overall $\mathrm{TiO}_{2}$ content of the continuous ejecta of Zhinyu crater is relatively low (see section 4.1), making it not suitable for subdivision. Consequently, to evaluate the mineral composition of the ejecta around Zhinyu crater, mineral maps (Fig. 2) of clinopyroxene (CPX), orthopyroxene (OPX), olivine (OL) and plagioclase (PLG) were extracted from the MI derived global map products (Lemelin et al., 2016). It emerges that three rings with varied mineral abundance, in particular for the OL (Fig. 2a), are distributed concentrically around the Zhinyu crater. The boundaries of these three rings are broadly outlined by the OL variation (Lai et al., 2020) and defined in this study as Im1, $\operatorname{Im} 2$ and $\operatorname{Im} 3$, in the order from the rim outward (Fig. 2). Previous studies have proposed buried mare basalts fields inside the Von Kármán crater (Pasckert et al., 2018; Ling et al., 2019). Here the spectral/mineralogical variations suggest there might have been at least three distinct mare flooding events with a degree of compositional differences. 


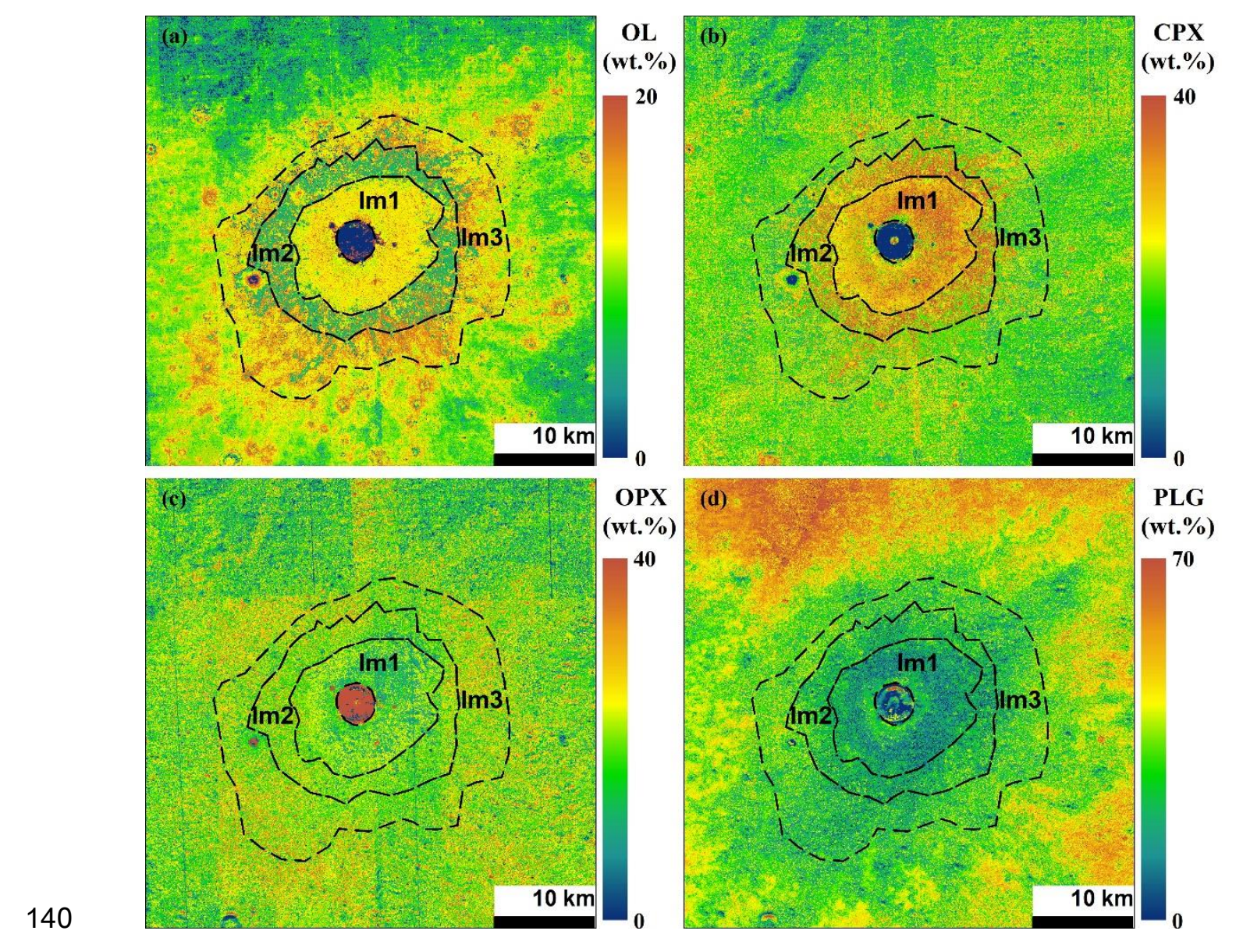

141 Fig. 2. Three mineral abundance variation rings distributed concentrically around

142 the Zhinyu crater. (a) OL; (b) CPX; (c) OPX; (d) PLG. These MI derived products are

143 from Lemelin et al. (2016). Upper range boundaries differ to highlight variations.

\section{4}

\subsection{Olivine composition analysis}

The olivine fraction content of igneous rocks is highly diagnostic for interpreting

147 the magma source and the degree of petrologic evolution (Isaacson et al., 2011). Based

148 on the established relation between laboratory spectral absorption features and OL

149 composition (Sunshine and Pieters, 1998; Isaacson and Pieters, 2010), the relative

$150 \mathrm{Mg} /(\mathrm{Mg}+\mathrm{Fe})$ ratio, as known as the forsterite number (Fo\#), can be estimated from

151 the remotely-sensed spectra. Therefore, the average spectrum of each layer was

152 extracted from $\mathrm{M}^{3}$ images (Supplementary Fig. 1) and deconvolved by the Modified 
Gaussian Model (MGM) (Supplementary Figs. 2-4) (Sunshine and Pieters, 1993) with different mineral combination configurations (Supplementary Table 1) to estimate mineral modes (Clénet et al., 2011; Clénet et al., 2013). The OL composition is determined by fitting the MGM-derived OL-related absorption centers to a laboratoryderived compositional trend line (Sunshine and Pieters, 1998; Isaacson and Pieters, 2010). The uncertainty of the predicted Fo\# values that arises from model initial conditions and other error sources, e.g., the low signal-to-noise ratio and low resolution of $\mathrm{M}^{3}$ spectrum, is estimated to be about $10 \%$ Fo\# \# and possibly more in the case of ternary mineral mixtures (Isaacson and Pieters, 2010; Pinet et al., 2018; Pinet et al., 2019).

\subsection{Basalt layer thickness estimation}

For a lunar simple crater with a diameter smaller than $15 \mathrm{~km}$, the maximum excavation depth $\left(H_{e x c}\right)$ is approximately $1 / 10$ of the transient crater diameter $\left(D_{t}\right)$, which is about 0.84 times the rim-to-rim diameter $(D)$, i.e., $D_{t}=0.84 D$ (Melosh, 1989). The ejecta apron of an impact crater is composed of target materials excavated during the excavation stage (Melosh, 1989). They are deposited around the crater following an inverted pre-impact stratigraphy of the underlying bedrock: the materials from the shallower depths tend to be thrown farther away from the crater rim than materials excavated from deeper layers (Thomson et al., 2009). The ejecta becomes thinner and more mixed with local mature regolith with increasing radial distance (Melosh, 1989). The average radius of continuous ejecta blanket $\left(R_{c e}\right)$ can be estimated from crater 
radius $(R)$ using the relation $\mathrm{R}_{\mathrm{ce}}=\left(2.348_{-0.454}^{+0.564}\right) \mathrm{R}^{1.006}$ (Moore et al., 1974).

Although many laboratory experiments and numerical simulations have studied impacts into layered targets (e.g., Stöffler et al., 1975; Senft and Stewart, 2007; Prieur et al., 2018), little work has been done to specifically address the relationship between the radial position of ejecta on the upper surface of the continuous ejecta blanket and depth of excavation in layered targets (e.g., Baratoux et al., 2007; Thomson et al., 2009). As a first approximation in this study, it's assumed that continuous ejecta at the farthest distance $\left(D_{\max }\right)$ comes from the surface, and the radial position of the continuous ejecta blanket is inversely related to the excavation depth, i.e., $\left(H_{e x c}-S_{c e}\right) / H_{e x c}=D / D_{\max }$. Therefore, the source depth of continuous ejecta blanket $\left(S_{c e}\right)$ at a given radial position $(D)$ is estimated by equation $S_{c e}=H_{e x c}-\left(D * H_{e x c} / D_{\max }\right)$.

\section{Results and discussions}

\subsection{Composition variations}

Results of the MI-derived mineral abundances (Lemelin et al., 2016) for the three layers (in the order $\operatorname{Im} 1, \operatorname{Im} 2$, and $\operatorname{Im} 3$ ) show that the PLG abundance increases from $38.2 \%$ to $43.1 \%$, the CPX decreases from $26.3 \%$ to $18.8 \%$, the OPX increases from $22.6 \%$ to $25.2 \%$, and the OL decreases from $12.9 \%$ to $10.5 \%$ and then increases to 13.2\%. The mineral abundances almost fall within each other's standard deviation (Fig. 3), suggesting variations to be marginal. For example, the average CPX abundances for $\operatorname{Im} 1, \operatorname{Im} 2$ and $\operatorname{Im} 3$ are $\sim 26.3 \pm 5.3 \%, \sim 24.8 \pm 6.9 \%$ and $\sim 18.8 \pm 6.2 \%$, respectively. Also, the average OL abundances are $\sim 12.9 \pm 2.6 \%, \sim 10.5 \pm 4.7 \%$ and $\sim 13.2 \pm 3.4 \%$, respectively. MGM fitting results reveal that Fo\# values derived from OL-related 

sampled units.

200

201 respectively (Ling et al., 2015)), the identified three layers generally have relatively

Fig. 3. Mineral abundances of the identified three basalt layers. The error bars show the standard deviation of each mineral abundance.

The average $\mathrm{FeO}$ contents for $\operatorname{Im} 1, \operatorname{Im} 2$ and $\operatorname{Im} 3$ are $\sim 17.1 \pm 0.4 \%, \sim 16.6 \pm 0.4 \%$ and $\sim 15.9 \pm 0.5 \%$, respectively. Also, the average $\mathrm{TiO}_{2}$ contents are $\sim 1.5 \pm 0.4 \%, \sim 1.7 \pm 0.3 \%$ and $\sim 1.6 \pm 0.3 \%$, respectively (Fig. 4). Compared with lunar basalts sampled by Apollo and Luna missions or in situ measured by a rover (for example, the $\mathrm{FeO}$ and $\mathrm{TiO}_{2}$ contents of basalt measured by the Chang'e-3 rover are $\sim 22.8 \mathrm{wt} \%$ and $\sim 5.0 \mathrm{wt} \%$,

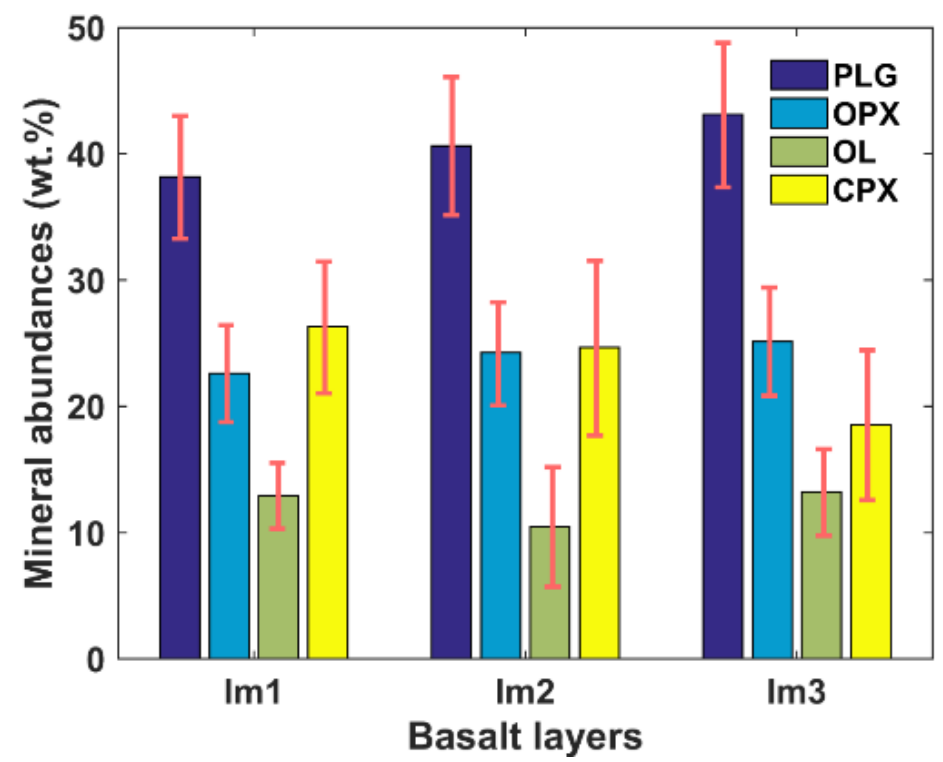
low $\mathrm{FeO}$ and $\mathrm{TiO}_{2}$ contents. 

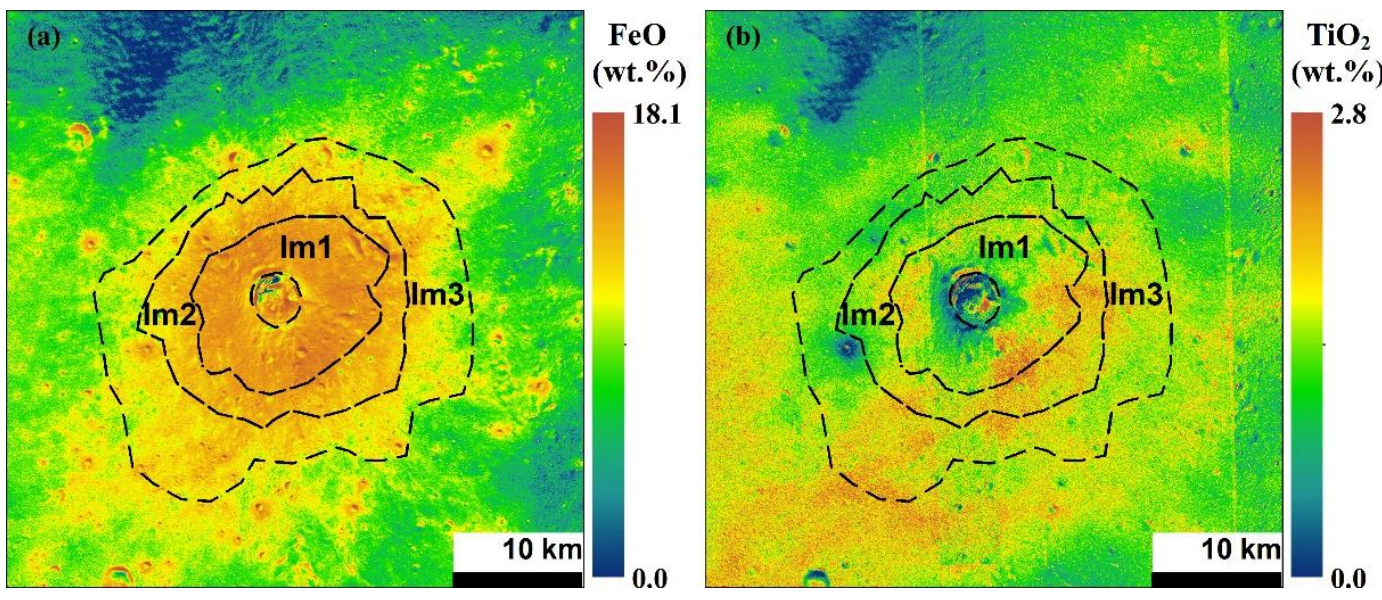

Fig. 4. $\mathrm{FeO}$ and $\mathrm{TiO}_{2}$ contents of identified three mare basalt layers.

213

\subsection{The thickness of the basalt layers}

Based on the excavation depth of impact crater (section 3.3), the maximum excavation depth $\left(H_{e x c}\right)$ and radius of continuous ejecta blanket $\left(R_{c e}\right)$ of Zhinyu cater are about $320 \mathrm{~m}$ and $11.4 \mathrm{~km}$, respectively. Because the extents of the identified three layers are outlined by irregular polygonal rings, the average ejecta range from each layer is approximated by the difference between the radius of a fitted circle of each layer and the radius of Zhinyu crater (Fig. 5). The results show that the extents of all the three identified layers are roughly within the maximum extent of the continuous ejecta. The average ejecta ranges of $\operatorname{Im} 1, \operatorname{Im} 2$ and $\operatorname{Im} 3$ are about $4.6 \mathrm{~km}, 7.6 \mathrm{~km}$ and $11.4 \mathrm{~km}$, indicating the extent of each layer is about 3.4, 5 and 7 times of Zhinyu crater's radius, respectively. Therefore, the thicknesses of the proposed three basalt layers (from top to bottom) are estimated to be about $107 \mathrm{~m}, 84 \mathrm{~m}$ and $129 \mathrm{~m}$, respectively. It is important to note that it cannot be determined whether the Zhinyu impact had penetrated the entire $\operatorname{Im} 1$ layer in this study. Therefore, the overall thickness of three mare basalt layers is estimated to be at least $320 \mathrm{~m}$. Because large portions of the northeastern region of the Von Kármán crater floor are mantled by the ejecta from the 
229 Finsen crater, and the area of the mare unit is about $6145 \mathrm{~km}^{2}$ (Pasckert et al., 2018), a 230 minimum mare volume is thus estimated to be about $1966 \mathrm{~km}^{3}$.

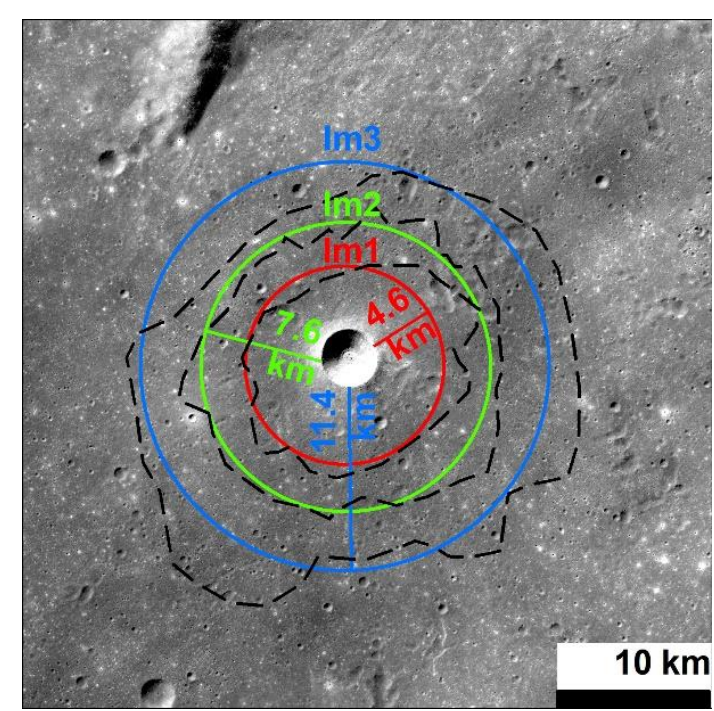

Fig. 5. Approximation of ejecta range around Zhinyu crater.

Ling et al. (2019) divided the mare region inside the Von Kármán crater into LowTi unit $\left(1.5 \mathrm{wt} \%<\mathrm{TiO}_{2}<3 \mathrm{wt} \%\right)$ and Finsen ejecta unit $\left(\mathrm{TiO}_{2}<1.5 \mathrm{wt} \%\right)$. Crater sizefrequency distribution (CSFD) measurements of the Low-Ti mare unit show three absolute model ages (AMAs), i.e., 3.38 Ga, 3.57 Ga, and 3.72 Ga (Ling et al., 2019). These AMAs indicate there might be older buried lava flows in the Von Kármán crater (Pasckert et al., 2018; Ling et al., 2019), and the composition variations (Fig. 3) highlighted in this study indicate the recent erupted basalt (Im3) might have a lower CPX/OPX ratio than the older basalts (Im1). The kink (deflection diameter) between the youngest $(3.38 \mathrm{Ga})$ and oldest (3.72) isochron curves is $\sim 1 \mathrm{~km}$, suggesting the thickness of buried lava flows to be $>100 \mathrm{~m}$ (Ling et al., 2019). The estimated total basalt thickness $(\geq 320 \mathrm{~m})$ in this study agrees with this estimate. As a result, a refined stratigraphic sequence for the low-Ti mare basalts (Ling et al., 2019; Qiao et al., 2019; 

$\mathrm{m})$, and $\operatorname{Im} 1(\geq 129 \mathrm{~m})$.

A Lunar Penetrating Radar (LPR), with two work frequency channels (channel 1, $60 \mathrm{MHz}$; channel 2, $500 \mathrm{MHz}$ ), is part of the instrumentation on the Yutu-2 rover to study the subsurface structure of its traversing area (Fang et al., 2014; Jia et al., 2018). Initial interpretations of the data indicate that there are several subsurface layers/units,

252 pointing to a complex thermal history. For example, the high-frequency LPR data reveal 253 that the shallow subsurface at the landing area is roughly composed of three layers (Lai 254 et al., 2019; Li et al., 2020; Zhang et al., 2020a; Zhang et al., 2020b): a topmost fine255 grained regolith layer (depth, 0 to $12 \mathrm{~m}$ ), an intermediate layer consisting of coarse 256 materials with embedded rocks (12 to $24 \mathrm{~m}$ ), and a bottom layer composed of 257 alternating coarse and fine materials (24 to $40 \mathrm{~m}$ ). As of November 22, 2020, the Yutu2582 rover had already operated for 24 lunar days and traversed about $590 \mathrm{~m}$ on the Finsen 259 ejecta unit within the Von Kármán crater. The rover is currently about 30 km away from 260 the Zhinyu crater. The collected low-frequency LPR channel has the maximum 261 detection depth of $330 \mathrm{~m}$ (Lai et al., 2020), possibly up to 500 m (Zhang et al., 2020a). 262 However, due to the low thickness resolution $(\sim 10 \mathrm{~m})$ of the LPR low-frequency data 263 and different processing procedures, the deep multi-layered stratigraphic structure 264 revealed by the low-frequency LPR data is not entirely consistent between most of the 265 studies, including Lai et al. (2020), Zhang et al. (2020a), and Zhang et al. (2020b). 266 Nevertheless, the basaltic stratigraphic sequence at the Zhinyu crater proposed in this study roughly corresponds to the D and E layers in the work of Lai et al. (2020). The 
rover will continue to traverse westward and it is planned to reach the mare basalt area in the future. The proposed stratigraphic sequence and basalt thickness are expected to be validated by the LPR data, which will provide ground truth and should contribute to a fuller understanding of the basalt thermal history of the Von Kármán crater.

\subsection{Implications for magma evolution}

The ejecta under investigation is composed of materials exhumed by the Zhinyu crater during formation, a process that inverts the target's stratigraphical sequence. Therefore, the variation of ejecta composition along the radial distances around Zhinyu crater reflects the compositional variation of the basalt source at different stratigraphic depths. A fairly homogenous OL composition (Fo\#: 55) of the three layers indicates the sources of these mare basalts $(\geq 320 \mathrm{~m}$ in thickness) are almost homogenous in composition, or might even be from a single magma chamber. Generally, for primary magmas, forsteritic (high Fo\#) OL is indicative of a primitive source, and more fayalitic (low Fo\#) OL is indicative of an evolved source (Basaltic Volcanism Study Project, 1981). The predicted Fo\# value points to a moderate magma evolution. The small mineral abundance differences (Fig. 3) among layers may indicate there were at least three mare flooding events occurred inside Von Kármán crater during the Imbrian period, with two dome-like structures being the possible latest volcanic vents of these basalts (Qiao et al., 2019).

\section{Conclusion}


flooded with mare basalts during the Imbrian period. Zhinyu, a fresh impact crater, is the largest close to the landing site. The materials exhumed by the blast would have distributed the ejecta around the crater, exposing the stratigraphy sequence of the underlying basaltic rock layer(s). The mineral abundances derived from multispectral data, vary radially and discontinuously from the rim craters outwards, forming compositionally distinguished annuli. In particular, variations in the mineral olivine and clinopyroxene abundances support the idea that there could be at least three distinct basalt layers (named $\operatorname{Im} 1, \operatorname{Im} 2$, and $\operatorname{Im} 3$ from bottom to top) within the Von Kármán crater. The thickness of each layer is estimated by an empirical relation according to the processes of impact excavation and ejecta deposition, i.e., the shallow material deposits at the further distance whereas the deep material deposits around the crater. As it cannot be determined in this study whether the Zhinyu impact penetrated through the entire Im1 layer, the total thickness of the three basalt layers is estimated to be at least $320 \mathrm{~m}$. However, the minor differences noted in the mineral abundances and the fairly consistent olivine compositions (Fo\#: 55) of these three layers indicate the sources of these mare basalts to be comparable in composition, perhaps even from a single magma chamber where the magma underwent only moderate evolution. The westward traversing Yutu-2 rover may provide ground truth for the findings in this study, which would contribute to the understanding of the thermal history of the Von Kármán crater.

\section{Declaration of competing interest}

The authors declare that they have no known competing financial interests 
or personal relationships that could have appeared to influence the work 314 reported in this article.

\section{Acknowledgments}

The $\mathrm{M}^{3}$ data are from PDS Geoscience Node (https://pdsgeosciences.wustl.edu/). The MI data are from Selene Data Archive 319 (http://12db.selene.darts.isas.jaxa.jp/). The MI-derived mineral maps are from 320 (https://astrogeology.usgs.gov/maps/lunar-kaguya-multiband-imager-mosaics). 321 This work was supported by the Strategic Priority Research Program of Chinese Academy of Sciences (grant No. XDB41000000), National Natural Science 323 Foundation of China (grant Nos. 41702354 and 41941003), Macao Young Scholars 324 Program (grant No. AM201902), and Science and Technology Development Fund of 325 Macau (grant No. 131/2017/A3).

\section{Supplementary material}

Supplementary material associated with this article can be found in the online version.

\section{References}

Baratoux, D., Pinet, P., Gendrin, A., Kanner, L., Mustard, J., Daydou, Y., Vaucher, J., Bibring, J.-P., 2007. Mineralogical structure of the subsurface of Syrtis Major from OMEGA observations of lobate ejecta blankets. Journal of 
Besse, S., Yokota, Y., Boardman, J., Green, R., Haruyama, J., Isaacson, P., Mall, U., Matsunaga, T., Ohtake, M., Pieters, C., Staid, M., Sunshine, J., Yamamoto, S., 2013. One Moon, many measurements 2: Photometric corrections. Icarus. 226 (1), 127-139.

Basaltic Volcanism Study Project, 1981. Basaltic Volcanism on the Terrestrial Planets. Pergamon Press, New York.

Clénet, H., Pinet, P. C., Daydou, Y., Heuripeau, F., Rosemberg, C., Baratoux, D., Chevrel, S., 2011. A new systematic approach using the Modified Gaussian Model: Insight for the characterization of chemical composition of olivines, pyroxenes and olivine-pyroxene mixtures. Icarus. 213 (1),

Clénet, H., Pinet, P., Ceuleneer, G., Daydou, Y., Heuripeau, F., Rosemberg, C., Bibring, J. P., Bellucci, G., Altieri, F., Gondet, B., 2013. A systematic mapping procedure based on the Modified Gaussian Model to characterize magmatic units from olivine/pyroxenes mixtures: Application to the Syrtis Major volcanic shield on Mars. Journal of Geophysical Research: Planets. 118 (8), 1632-1655.

Clark, R. N., Pieters, C. M., Green, R. O., Boardman, J. W., Petro, N. E., 2011. Thermal removal from near-infrared imaging spectroscopy data of the Moon. Journal of Geophysical Research: Planets. 116 (E6), E00G16.

Di, K., Liu, Z., Liu, B., Wan, W., Peng, M., Wang, Y., Gou, S., Yue, Z., Xn, X., 
Jia, M., Niu, S., 2019a. Chang'e-4 lander localization based on multisource data. Journal of Remote Sensing. 23 (1), 177-184.

Di, K., Zhu, M.-H., Yue, Z., Lin, Y., Wan, W., Zhaoqin Liu, Gou, S., Liu, B., 360 rover. Earth and Planetary Science Letters. 528, 115829.

378 Gou, S., Di, K., Yue, Z., Liu, Z., He, Z., Xu, R., Liu, B., Peng, M., Wan, W., 
Wang, Y., Liu, J., 2020. Forsteritic olivine and magnesium-rich orthopyroxene materials measured by Chang'e-4 rover. Icarus. 345, 113776.

Hiesinger, H., Jaumann, R., 2014 Chapter 23 - The Moon. In: Spohn, T., Breuer, D., Johnson, T. V., (Eds.), Encyclopedia of the Solar System (Third Edition). Elsevier, Boston, pp. 493-538.

Hu, X., Ma, P., Yang, Y., Zhu, M.-H., Jiang, T., Lucey, P. G., Sun, L., Zhang, H., Li, C., Xu, R., He, Z., Lin, H., Huang, C., Sun, Y., 2019. Mineral abundances inferred from in-situ reflectance measurements of Chang'E4 landing site in South Pole-Aitken basin. Geophysical Research Letters. 46, 9439-9447.

Huang, J., Xiao, Z., Flahaut, J., Martinot, M., Head, J., Xiao, X., Xie, M., Xiao, L., 2018. Geological Characteristics of Von Kármán Crater, Northwestern South Pole-Aitken Basin: Chang'E-4 Landing Site Region. Journal of Geophysical Research: Planets. 123 (7), 1684-1700.

Huang, J., Xiao, Z., Xiao, L., Horgan, B., Hu, X., Lucey, P., Xiao, X., Zhao, S., Qian, Y., Zhang, H., Li, C., Xu, R., He, Z., Yang, J., Xue, B., He, Q., Zhong, J., Lin, H., Huang, C., Xie, J., 2020. Diverse rock types detected in the lunar South Pole-Aitken Basin by the Chang'E-4 lunar mission. Geology. 48, 723-727.

Isaacson, P. J., Pieters, C. M., 2010. Deconvolution of lunar olivine reflectance spectra: Implications for remote compositional assessment. Icarus. 210 
402 Isaacson, P. J., Pieters, C. M., Besse, S., Clark, R. N., Head, J. W., Klima, R. L., Mustard, J. F., Petro, N. E., Staid, M. I., Sunshine, J. M., 2011. Remote compositional analysis of lunar olivine- rich lithologies with Moon Mineralogy Mapper $\left(\mathrm{M}^{3}\right)$ spectra. Journal of Geophysical Research: Planets. 116 (E6), E00G11.

Jia, Y., Zou, Y., Ping, J., Xue, C., Yan, J., Ning, Y., 2018. The scientific objectives and payloads of Chang'E-4 mission. Planetary and Space Science. 162, 207-215.

Lai, J., Xu, Y., Zhang, X., Xiao, L., Yan, Q., Meng, X., Zhou, B., Dong, Z., Zhao, D., 2019. Comparison of Dielectric Properties and Structure of Lunar Regolith at Chang'e-3 and Chang'e-4 Landing Sites Revealed by Ground Penetrating Radar. Geophysical Research Letters. 46, 12783-12793.

Lai, J., Xu, Y., Bugiolacchi, R., Meng, X., Xiao, L., Xie, M., Liu, B., Di, K., Zhang, X., Zhou, B., Shen, S., Xu, L., 2020. First look by the Yutu-2 rover at the deep subsurface structure at the lunar farside. Nature Communications. 11 (1), 3426.

Lemelin, M., Lucey, P. G., Gaddis, L. R., Hare, T., Ohtake, M., 2016. Global map products from the Kaguya Multiband Imager at 512 ppd: Minerals, FeO and OMAT. 47th Lunar and Planetary Science Conference, the Woodlands, Texas, pp. 2994.

Li, C., Su, Y., Pettinelli, E., Xing, S., Ding, C., Liu, J., Ren, X., Lauro, S. E., 
Soldovieri, F., Zeng, X., Gao, X., Chen, W., Dai, S., Liu, D., Zhang, G., Zuo, W., Wen, W., Zhang, Z., Zhang, X., Zhang, H., 2020. The Moon's farside shallow subsurface structure unveiled by Chang'E-4 Lunar Penetrating Radar. Science Advances. 6 (9), eaay6898.

Lin, H., He, Z., Yang, W., Lin, Y., Xu, R., Zhang, C., Zhu, M.-H., Chang, R., Zhang, J., Li, C., Lin, H., Liu, Y., Gou, S., Wei, Y., Hu, S., Xue, C., Yang, J., Zhong, J., Fu, X., Wan, W., Zou, Y., 2020. Olivine-norite rock detected by the lunar rover Yutu-2 likely crystallized from the SPA impact melt pool. National Science Review. 7, 913-920.

Ling, Z., Jolliff, B. L., Wang, A., Li, C., Liu, J., Zhang, J., Li, B., Sun, L., Chen, J., Xiao, L., Liu, J., Ren, X., Peng, W., Wang, H., Cui, X., He, Z., Wang, J., 2015. Correlated compositional and mineralogical investigations at the Chang'e-3 landing site. Nature Communications. 6, 8880.

Ling, Z., Qiao, L., Liu, C., Cao, H., Bi, X., Lu, X., Zhang, J., Fu, X., Li, B., Liu, J., 2019. Composition, mineralogy and chronology of mare basalts and non-mare materials in Von Kármán crater: Landing site of the Chang'E-4 mission. Planetary and Space Science. 179, 104741.

Lucey, P. G., Taylor, G. J., Hawke, B. R., Spudis, P. D., 1998. FeO and TiO2 concentrations in the South Pole-Aitken basin: Implications for mantle composition and basin formation. Journal of Geophysical Research: Planets. 103 (E2), 3701-3708.

Melosh, H. J., 1989. Impact Cratering: A geologic process. Oxford University 
446 Moore, H. J., Hodges, C. A., Scott, D. H., 1974. Multiringed basins - illustrated by Orientale and associated features. 5th Lunar Science Conference, Houston, Texas, pp. 71-100.

449

450

451

452

453

Ohtake, M., Haruyama, J., Matsunaga, T., Kodama, S., Morota, T., Yokota, Y., 2008. Scientific objectives and specification of the SELENE Multiband Imager. Advances in Space Research. 42 (2), 301-304.

Otake, H., Ohtake, M., Hirata, N., 2012. Lunar Iron and Titanium Abundance Algorithms Based on SELENE (Kaguya) Multiband Imager Data. 43rd Lunar and Planetary Science Conference, the Woodlands, Texas, pp. 1905.

Pasckert, J. H., Hiesinger, H., van der Bogert, C. H., 2018. Lunar farside volcanism in and around the South Pole-Aitken basin. Icarus. 299, 538562.

Pieters, C. M., Boardman, J., Buratti, B., Chatterjee, A., Clark, R., Glavich, T., Green, R., Head, J., Isaacson, P., Malaret, E., 2009. The Moon mineralogy mapper (M3) on Chandrayaan-1. Current Science. 96 (4), 500-505.

Pinet, P. C., Chevrel, S. D., Daydou, Y. H., 2018. Characterization of the Olivine/Plagioclase Mineralogy at Copernicus Crater from MGM Deconvolution of M3 Observations. 49th Lunar and Planetary Science Conference, the Woodlands, Texas, pp. 1899.

Pinet, P. C., 2019. The Moon's mantle unveiled. Nature. 569 (7756), 338-339.

Pinet, P. C., Chevrel, S. D., Daydou, Y. H., 2019. Reassessing the relationship 
between olivine composition and reflectance Spectroscopy from advanced MGM deconvolution. 50th Lunar and Planetary Science Conference, the Woodlands, Texas, pp. 1806.

Prieur, N. C., Rolf, T., Wünnemann, K., Werner, S. C., 2018. Formation of Simple Impact Craters in Layered Targets: Implications for Lunar Crater Morphology and Regolith Thickness. Journal of Geophysical Research: Planets. 123 (6), 1555-1578.

Qiao, L., Ling, Z., Fu, X., Li, B., 2019. Geological characterization of the Chang'e-4 landing area on the lunar farside. Icarus. 333, 37-51.

Ren, X., Liu, J. J., Wang, F. F., Wang, W. R., Mu, L. L., Li, H. H., 2014. A New lunar global topographic map products from Chang'E-2 Stereo Camera Image Data. European Planetary Science Congress, Cascais, Portugal, pp. EPSC2014-344.

Senft, L. E., Stewart, S. T., 2007. Modeling impact cratering in layered surfaces. Journal of Geophysical Research: Planets. 112 (E11), E11002.

Stöffler, D., Gault, D. E., Wedekind, J., Polkowski, G., 1975. Experimental hypervelocity impact into quartz sand: Distribution and shock metamorphism of ejecta. Journal of Geophysical Research. 80 (29), 40624077.

Stuart-Alexander, D. E., 1978. Geologic map of the central far side of the Moon. Sunshine, J. M., Pieters, C. M., 1993. Estimating modal abundances from the spectra of natural and laboratory pyroxene mixtures using the modified 
490 Sunshine, J. M., Pieters, C. M., 1998. Determining the composition of olivine from reflectance spectroscopy. Journal of Geophysical Research. 103 (E6), 13675-13688.

493

494

495

496

497

498

499

500

501

502

503

504

505

506

507

Thomson, B. J., Grosfils, E. B., Bussey, D. B. J., Spudis, P. D., 2009. A new technique for estimating the thickness of mare basalts in Imbrium Basin. Geophysical Research Letters. 36 (12), L12201.

Yingst, R. A., Chuang, F. C., Berman, D. C., Mest, S. C., 2017. Geologic Mapping of the Planck Quadrangle of the Moon (LQ-29). 48th Lunar and Planetary Science Conference, the Woodlands, Texas, pp. 1680.

Zhang, J., Zhou, B., Lin, Y., Zhu, M.-H., Song, H., Dong, Z., Gao, Y., Di, K., Yang, W., Lin, H., Yang, J., Liu, E., Wang, L., Lin, Y., Li, C., Yue, Z., Yao, Z., Ouyang, Z., 2020a. Lunar regolith and substructure at Chang'E-4 landing site in South Pole-Aitken basin. Nature Astronomy. https://doi.org/10.1038/s41550-020-1197-x.

Zhang, L., Li, J., Zeng, Z., Xu, Y., Liu, C., Chen, S., 2020b. Stratigraphy of the Von Kármán Crater Based on Chang'E-4 Lunar Penetrating Radar Data. Geophysical Research Letters. 47 (15), e2020GL088680. 


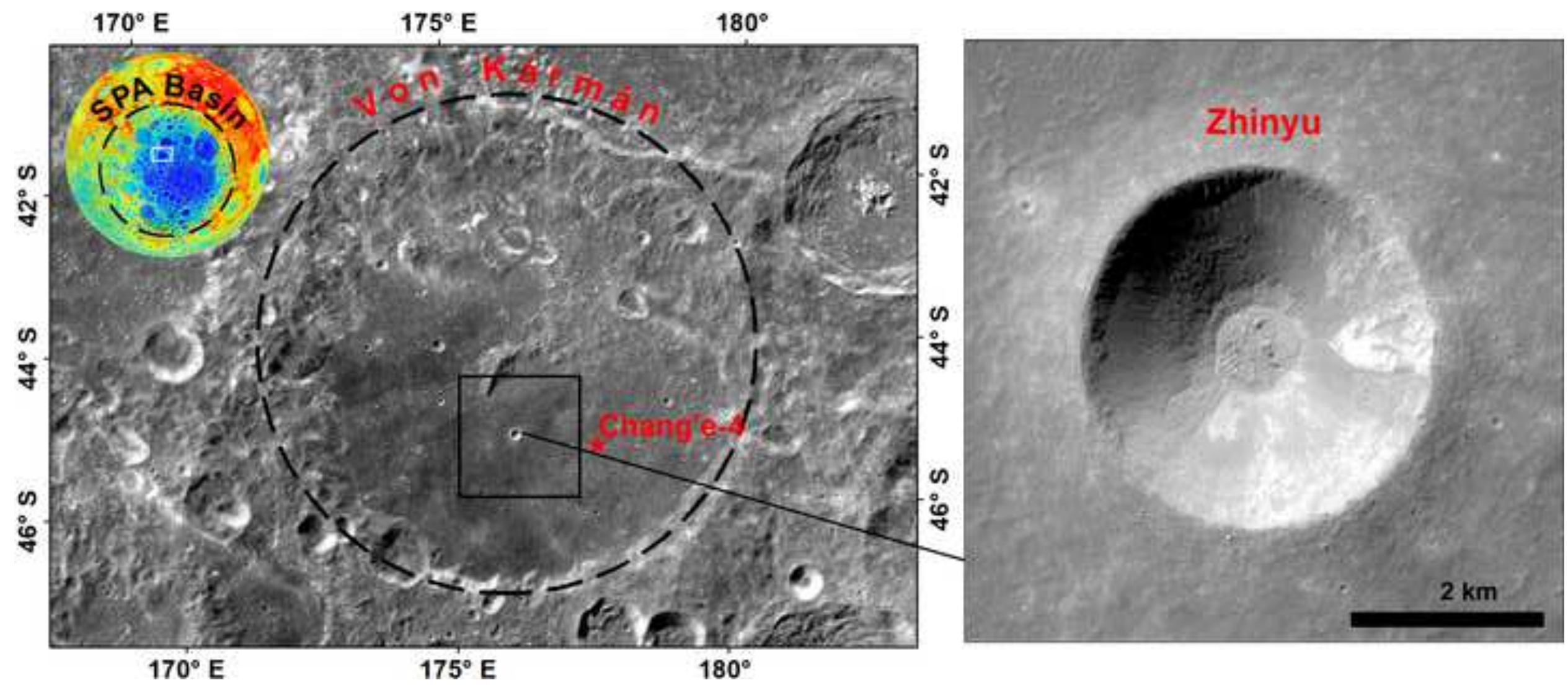




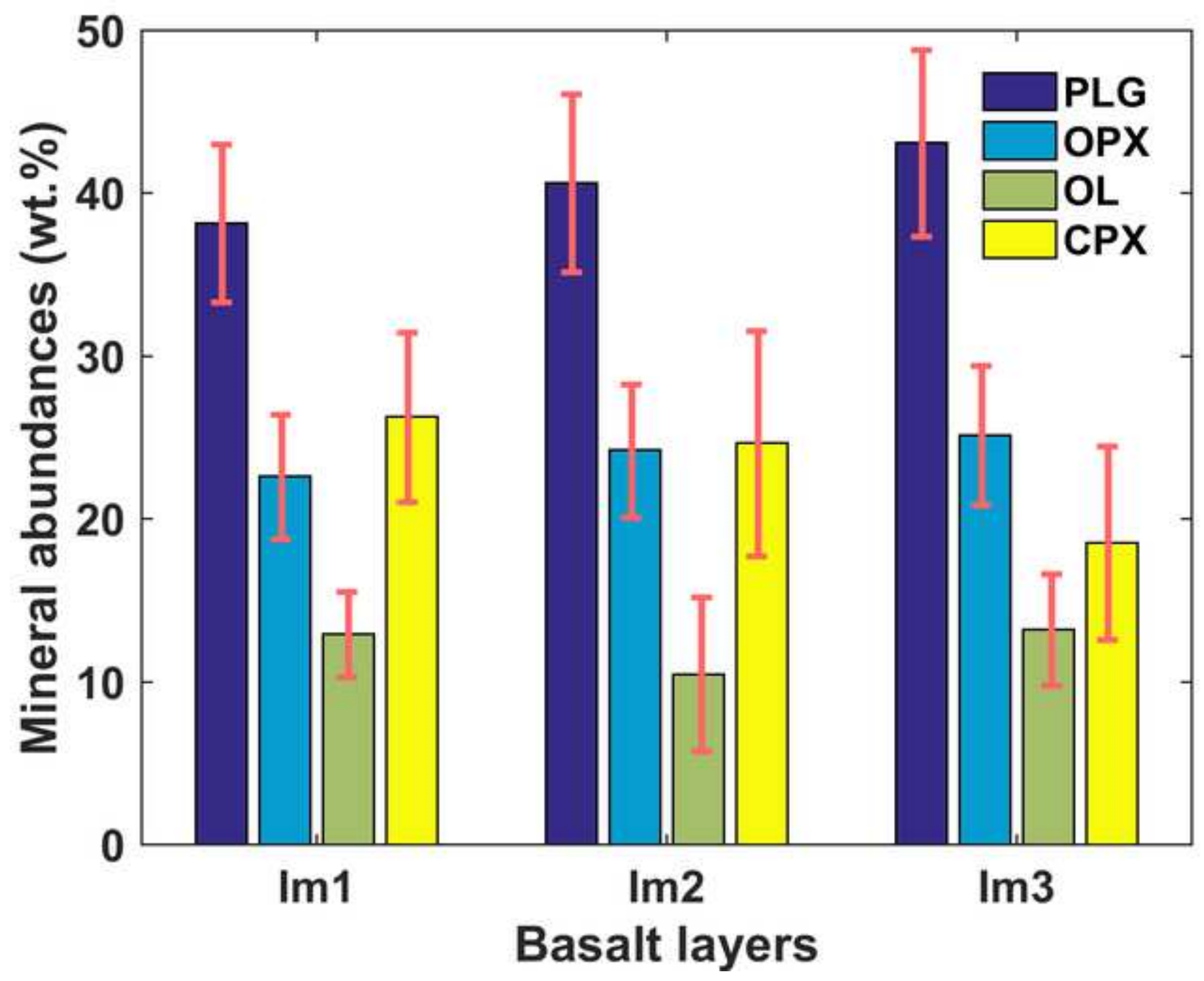



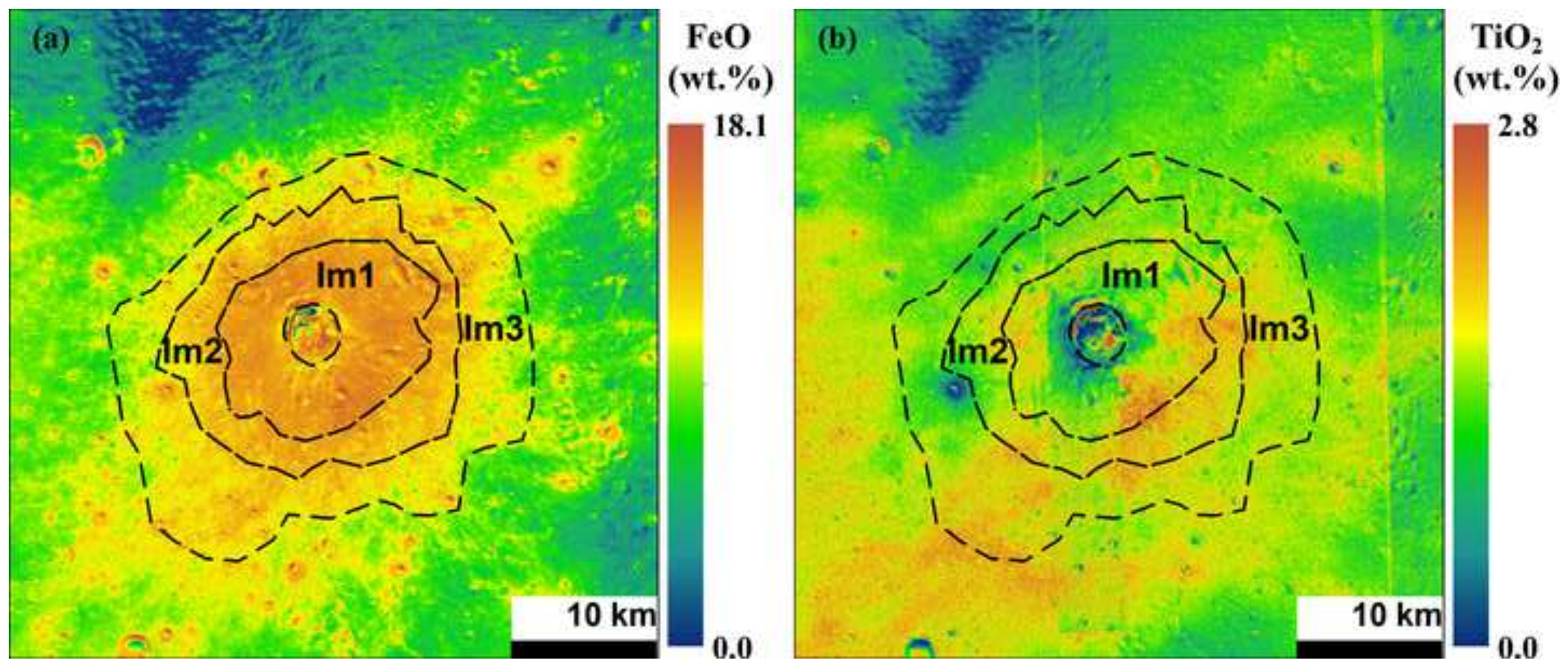


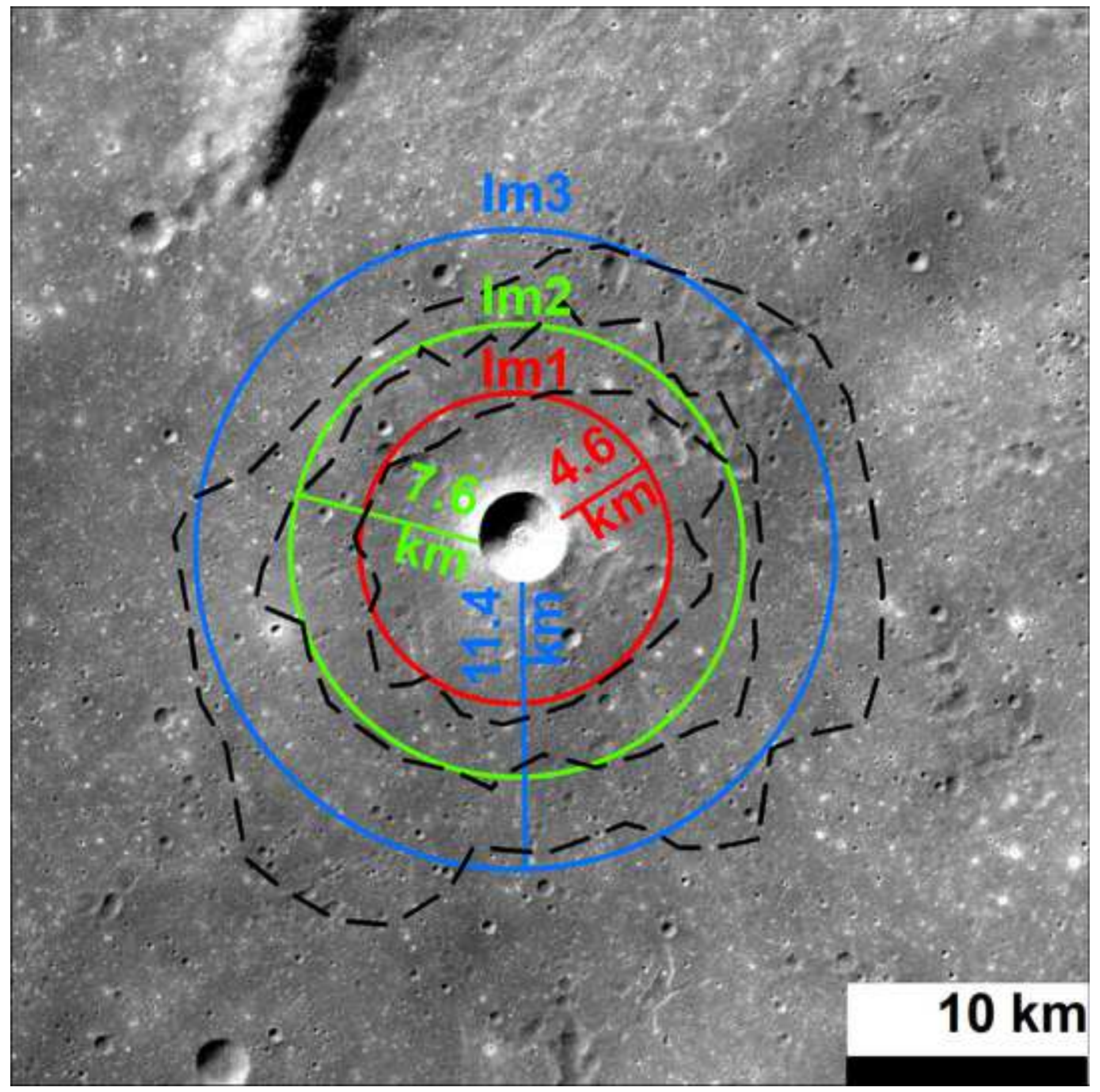


Click here to access/download e-Component

Mare basalt flooding revealed by Zhinyu crater_SM_1208.docx 